\title{
ORIGINAL
}

\section{Impact of the driving pressure on mortality in obese and non-obese ARDS patients: a retrospective study of 362 cases}

\author{
Audrey De Jong ${ }^{1}$, Jeanne Cossic ${ }^{2}$, Daniel Verzilli², Clément Monet ${ }^{2}$, Julie Carr², Mathieu Conseil², \\ Marion Monnin ${ }^{2}$, Moussa Cisse ${ }^{2}$, Fouad Belafia ${ }^{2}$, Nicolas Molinari ${ }^{3}$, Gérald Chanques ${ }^{1}$ and Samir Jaber ${ }^{* *}$
}

(c) 2018 Springer-Verlag GmbH Germany, part of Springer Nature and ESICM

\begin{abstract}
Purpose: The relation between driving pressure (plateau pressure-positive end-expiratory pressure) and mortality has never been studied in obese ARDS patients. The main objective of this study was to evaluate the relationship between 90-day mortality and driving pressure in an ARDS population ventilated in the intensive care unit (ICU) according to obesity status.

Methods: We conducted a retrospective single-center study of prospectively collected data of all ARDS patients admitted consecutively to a mixed medical-surgical adult ICU from January 2009 to May 2017. Plateau pressure, compliance of the respiratory system (Crs) and driving pressure of the respiratory system within $24 \mathrm{~h}$ of ARDS diagnosis were compared between survivors and non-survivors at day 90 and between obese (body mass index $\geq 30 \mathrm{~kg} / \mathrm{m}^{2}$ ) and non-obese patients. Cox proportional hazard modeling was used for mortality at day 90 .

Results: Three hundred sixty-two ARDS patients were included, 262 (72\%) non-obese and 100 (28\%) obese patients. Mortality rate at day 90 was respectively $47 \%(95 \% \mathrm{Cl}, 40-53)$ in the non-obese and $46 \%(95 \% \mathrm{Cl}, 36-56)$ in the obese patients. Driving pressure at day 1 in the non-obese patients was significantly lower in survivors at day 90 $\left(11.9 \pm 4.2 \mathrm{cmH}_{2} \mathrm{O}\right)$ than in non-survivors $\left(15.2 \pm 5.2 \mathrm{cmH}_{2} \mathrm{O}, p<0.001\right)$. Contrarily, in obese patients, driving pressure at day 1 was not significantly different between survivors $\left(13.7 \pm 4.5 \mathrm{cmH}_{2} \mathrm{O}\right)$ and non-survivors $\left(13.2 \pm 5.1 \mathrm{cmH}_{2} \mathrm{O}\right.$, $p=0.41)$ at day 90. After three multivariate Cox analyses, plateau pressure $[H R=1.04$ (95\% $\mathrm{Cl} 1.01-1.07)$ for each point of increase], $\mathrm{Crs}[\mathrm{HR}=0.97(95 \% \mathrm{Cl} 0.96-0.99)$ for each point of increase] and driving pressure [HR=1.07 (95\% Cl 1.04-1.10) for each point of increase], respectively, were independently associated with 90-day mortality in non-obese patients, but not in obese patients.
\end{abstract}

Conclusions: Contrary to non-obese ARDS patients, driving pressure was not associated with mortality in obese ARDS patients.

Keywords: Intensive care unit, Critical care, Obesity, Obese, Acute respiratory distress syndrome, Driving pressure

\footnotetext{
*Correspondence: s-jaber@chu-montpellier.fr

${ }^{1}$ Anesthesiology and Intensive Care; Anesthesia and Critical Care Department B, Saint Eloi Teaching Hospital, PhyMedExp, University of Montpellier, INSERM U1046, CNRS, UMR 9214, 80 Avenue Augustin Fliche, 34295 Montpellier Cedex 5, France

Full author information is available at the end of the article
}

Audrey De Jong and Jeanne Cossic have contributed equally from this work.

\section{Introduction}

Obesity has become a worldwide health concern. The prevalence of obese adults worldwide has risen significantly over 25 years [1]. Admissions to intensive care units (ICUs) for complications of bariatric surgery or other surgical or medical reasons are becoming increasingly frequent in obese patients [2]. Obese patients

\section{望 Springer}


represent a specific population in the ICU, particularly regarding respiratory care [3-5]. The acute respiratory distress syndrome (ARDS) incidence is increased in obese patients [6,7]. Response to specific treatments such as prone positioning [8] or noninvasive ventilation (NIV) preoxygenation is improved in this population [9-12]. The prognosis of ARDS is controversial, but overall it seems that obese ARDS patients have a lower mortality risk than non-obese patients $[7,8,13]$. The pathophysiology of respiratory system management in obese patients differs from that of the non-obese patient. The negative effects of thoracic wall weight and abdominal fat mass on pulmonary compliance, leading to decreased functional residual capacity and arterial oxygenation, are exacerbated by a supine position and further worsened after general anesthesia and mechanical ventilation.

One of the main targets of respiratory critical care management of the obese patient is the successful management of the respiratory system. Some studies have suggested that higher driving pressure [driving pressure $=$ plateau pressure (Pplat) - positive end expiratory pressure (PEEP)] was associated with higher mortality in ARDS [14], with conflicting results [14-19].

However, no distinction was made between non-obese and obese patients in the different studies assessing the relationship between driving pressure and mortality. Patients were included without focusing on specific populations. Notably, the respiratory system includes the lung and chest wall, and the plateau pressure is related to both transalveolar pressure ("lung") and transthoracic pressure ("chest"). Chest compliance may be decreased in the obese compared with non-obese patient, being associated with an increase of transthoracic pressure [20]. Given the epidemiologic and pathophysiologic changes observed in this specific population of obese patients, one could hypothesize that the results found in non-obese patients cannot be extrapolated to obese patients without dedicated studies and that the obesity status could be a confounding factor in the relationship between driving pressure and mortality in overall ARDS patients. To our knowledge, no study has specifically evaluated the relationship between mortality and driving pressure in obese ARDS patients.

The main objective of this study was to determine the influence of the obesity status on the relationship between 90-day mortality and driving pressure in a population with ARDS ventilated in the ICU. The secondary objectives were to determine the influence of the obesity status on the relationship between 90-day mortality and plateau pressure and compliance of the respiratory system (Crs). Our hypotheses were that, contrary to

\section{Take-home message}

Unlike non-obese-ARDS patients, driving pressure was not associated with mortality in obese-ARDS patients. This study suggests that a pre-defined similar ventilator settings for both obese and nonobese patients may not fit all, since positive end-expiratory pressure requirements and resulting driving pressure of respiratory system might vary widely among patients because of individual anatomy and physiology.

non-obese patients, mortality was not associated with higher driving pressure, higher plateau pressure, or lower Crs in obese ARDS patients.

\section{Materials and methods Study design}

We conducted a retrospective analysis of prospectively collected data of all ARDS patients consecutively admitted to a 16-bed mixed medical-surgical adult ICU in a university teaching hospital between January 2008 and May 2017. We obtained approval from the local scientific and ethics committee of the "Comite d'Organisation et de Gestion de l'Anesthésie Réanimation" (COGAR) of the Montpellier University Hospital, who stated that no informed consent of the patient or next of kin was required.

\section{Data collection}

Patient body weight and height were measured at the time of ICU admission. In accordance with international standards [21], patients with a body mass index $(B M I) \geq 30 \mathrm{~kg} / \mathrm{m}^{2}$ were defined as obese. All consecutive obese patients hospitalized during the study period in a medical-surgical ICU were included in the study. Additional information on the data collection is available in the electronical supplement content.

\section{Inclusion criteria}

All consecutive ARDS patients were included. ARDS was identified based on the Berlin criteria consensus definition [22]: (1) timing: onset within 1 week of a known clinical insult or new or worsening respiratory symptoms; (2) chest imaging: bilateral opacities, not fully explained by effusions, lobar/lung collapse or nodules; (3) origin of edema: respiratory failure not fully explained by cardiac failure or fluid overload. ARDS diagnosis was retrospectively reviewed by two physicians, JC and ADJ. All included patients were ventilated with a lung-protective mechanical ventilation protocol as defined in the literature: low tidal volume $6 \mathrm{ml} / \mathrm{kg}$, limited plateau pressure and PEEP. Ventilatory parameters were set to avoid intrinsic PEEP. 


\section{End points}

ICU and hospital mortality rates were obtained using hospital electronic patient records. The primary end point was the mortality rate at 90 days (all-cause mortality). The secondary end points were the ICU mortality rate, ICU and hospital length of stay, duration of invasive mechanical ventilation, use of post-extubation noninvasive ventilation, prone positioning rate, pneumothorax occurrence and presence of ventilator-associated pneumonia.

\section{Statistical analysis}

First, a descriptive analysis was performed overall in nonobese and obese patients. Driving pressure, plateau pressure and Crs were also described according to the World Health Organization (WHO) classification of obesity. Then, a univariate analysis was done according to survival at day 90 in non-obese and obese patients. Quantitative variables were expressed as mean [standard deviation (SD)] or median (interquartile range, 25-75\%) and compared using the Student $t$ test or Wilcoxon test as appropriate (Gaussian or non-Gaussian variables). Qualitative variables were expressed as numbers (\%) and compared using the chisquare test or Fisher test as appropriate. In case of missing values, the number of missing values was clearly stated for each variable, and no replacement method was used. In case of missing values, a sensitivity analysis was done using the best-worst case analysis (results are presented in the supplemental content), and in case of similar results, a complete case analysis was performed [assuming missing data as missing completely at random (MCAR), listwise deletion].

Second, receiver-operating characteristic (ROC) curve analysis was performed to assess the ability of the driving pressure, plateau pressure and Crs to predict mortality in the obese and non-obese groups. The best threshold was determined using the Youden index [23]. Then, KaplanMeier analysis was performed to determine the survival lifetimes for 90-day survival, and a log-rank test was used to compare the two curves of driving pressure, plateau pressure and Crs according to the best threshold found for each variable. The hazard ratio (HR) of mortality at day 90 was obtained by the Cox method.

Third, multivariate Cox regression was performed to assess the relationship among driving pressure (forced variable), obesity status (forced variable) and mortality at day 90 in the overall population. Interactions between variables were tested. Age, SAPS II, SOFA score, comorbidities and ARDS characteristics were a priori planned to be entered in the model, and a stepwise procedure (with a threshold of $p<0.05$ to stay in the final model) was used to select the final model. HRs were provided for each variable included in the final model or the driving pressure according to the obesity status in case of significant interaction between the two variables. As driving pressure, plateau pressure and Crs are mathematically coupled and collinear within them, we used a specific Cox model for each variable, driving pressure (model 1), plateau pressure (model 2) and Crs (model 3) [15]. The effect of an inclusion period was assessed and not retained in the final model because it was not significant (data not shown). Then, the same analyses were separately performed in obese and nonobese patients. Statistical significance was considered at $p<0.05 ; p$ values were two-tailed. The statistical analysis was performed by the Medical Statistical Department of the Montpellier University Hospital with the help of statistical software (SAS, version 9.4; SAS Institute; Cary, NC).

\section{Results}

Of the 5409 patients admitted to the ICU during the study period, 400 with ARDS were identified. Figure 1 presents the flow chart of the study. Complete ventilatory data were available in 362 patients who were included, 262 (72\%) non-obese patients and 100 (28\%) obese patients. One hundred twelve patients (28\%) were already included in randomized studies: 7 in the PROSEVA [24], 42 in the BIRDS [25] and 49 in the LIVE study [26]. The main demographic characteristics of the included nonobese and obese patients are detailed in Table 1 (see supplementary Table 1 for characteristics of overall ARDS non-obese and obese patients and supplementary Table 2 for the analysis according to the WHO classification). The ventilatory characteristics of non-obese and obese included patients are shown in Table 2 .

In non-obese patients, the mortality rates in the ICU and at day 90 were $44 \%$ (95\% CI 38-50) and 47\% (95\% CI 40-53), respectively. Driving pressure at day 1 in the non-obese patients was significantly lower in survivors at day $90\left(12 \pm 4 \mathrm{cmH}_{2} \mathrm{O}\right)$ than in non-survivors $(15 \pm 5$

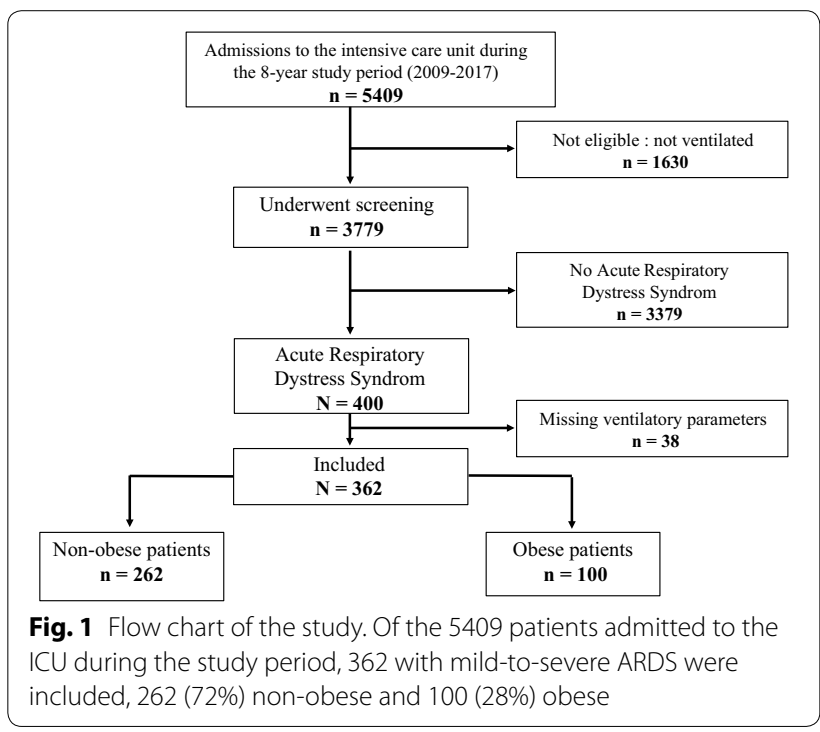


Table 1 Patients' characteristics in non-obese and obese patients

\begin{tabular}{|c|c|c|c|c|c|c|c|c|}
\hline \multirow{2}{*}{$\begin{array}{l}\text { Patients charac- } \\
\text { teristics }\end{array}$} & \multicolumn{2}{|c|}{ Overall $(n=362)$} & \multicolumn{2}{|c|}{ Non obese $(n=262)$} & \multirow[t]{2}{*}{$p$} & \multicolumn{2}{|c|}{ Obese $(n=100)$} & \multirow[t]{2}{*}{$p$ value } \\
\hline & $\begin{array}{l}\text { Non obese } \\
(n=262)\end{array}$ & Obese $(n=100)$ & $\begin{array}{l}\text { Survivors } \\
(n=140)\end{array}$ & $\begin{array}{l}\text { Non-survivors } \\
(n=122)\end{array}$ & & $\begin{array}{l}\text { Survivors } \\
(n=54)\end{array}$ & $\begin{array}{l}\text { Non-survivors } \\
(n=46)\end{array}$ & \\
\hline Age, years & $61 \pm 16$ & $60 \pm 11$ & $59 \pm 16$ & $62 \pm 16$ & 0.018 & $58 \pm 12$ & $63 \pm 10$ & 0.048 \\
\hline Male gender & $173(66)$ & $71(71)$ & $92(66)$ & $81(66)$ & 0.908 & $35(64)$ & $40(80)$ & 0.064 \\
\hline $\mathrm{BMI}, \mathrm{kg} / \mathrm{m}^{2}$ & $24 \pm 3$ & $36 \pm 7$ & $23 \pm 3$ & $24 \pm 3$ & 0.210 & $37 \pm 8$ & $35 \pm 6$ & 0.470 \\
\hline $\begin{array}{l}\text { Admission SAPS } \\
\text { II score }\end{array}$ & $54 \pm 17$ & $51 \pm 19$ & $48 \pm 14$ & $60 \pm 18$ & $<0.001$ & $44 \pm 16$ & $60 \pm 18$ & $<0.001$ \\
\hline $\begin{array}{l}\text { Admission SOFA } \\
\text { score }\end{array}$ & $10 \pm 5$ & $10 \pm 5$ & $8 \pm 4$ & $12 \pm 5$ & $<0.001$ & $9 \pm 4$ & $13 \pm 5$ & $<0.001$ \\
\hline Current smoker & $94(36)$ & $38(38)$ & $56(40)$ & $38(31)$ & 0.136 & $25(46)$ & $13(28)$ & 0.064 \\
\hline $\begin{array}{l}\text { Chronic alcohol- } \\
\text { ism }\end{array}$ & $81(31)$ & $32(32)$ & $50(36)$ & $31(25)$ & 0.114 & $13(24)$ & $19(41)$ & 0.066 \\
\hline $\begin{array}{c}\text { Systemic arterial } \\
\text { hypertension }\end{array}$ & $78(30)$ & $56(56)$ & $37(26)$ & $41(34)$ & 0.205 & $29(54)$ & $27(59)$ & 0.616 \\
\hline $\begin{array}{l}\text { Coronary artery } \\
\text { disease }\end{array}$ & $24(9)$ & $10(10)$ & $8(6)$ & $16(13)$ & 0.038 & $4(7)$ & $6(13)$ & 0.349 \\
\hline $\begin{array}{l}\text { Respiratory } \\
\text { disease }\end{array}$ & $38(15)$ & $13(13)$ & $18(13)$ & $20(16)$ & 0.417 & $8(15)$ & $5(11)$ & 0.559 \\
\hline Diabetes mellitus & $32(12)$ & $33(33)$ & $17(12)$ & $15(12)$ & 0.970 & $14(26)$ & $19(41)$ & 0.103 \\
\hline $\begin{array}{l}\text { Chronic renal } \\
\text { disease }\end{array}$ & $24(9)$ & $7(7)$ & $11(8)$ & $13(11)$ & 0.433 & $2(4)$ & $5(11)$ & 0.243 \\
\hline Cirrhosis & $58(22)$ & $23(23)$ & $27(19)$ & $31(25)$ & 0.234 & $8(15)$ & $15(33)$ & 0.035 \\
\hline \multicolumn{9}{|l|}{ Origin of ARDS } \\
\hline Primary & $123(47)$ & $39(39)$ & $70(50)$ & $53(43)$ & 0.289 & $21(39)$ & $18(39)$ & 0.980 \\
\hline Secondary & $139(53)$ & $61(61)$ & $70(50)$ & $69(57)$ & 0.289 & $33(61)$ & $27(59)$ & 0.806 \\
\hline \multicolumn{9}{|l|}{ ARDS severity } \\
\hline Mild & $22(8)$ & $6(6)$ & $11(8)$ & $11(9)$ & 0.740 & $3(6)$ & $3(7)$ & 1.000 \\
\hline Moderate & $117(45)$ & $49(49)$ & $70(50)$ & $47(39)$ & 0.080 & $26(48)$ & $23(51)$ & 0.769 \\
\hline Severe & $123(47)$ & $45(45)$ & $59(42)$ & $64(53)$ & 0.072 & $25(46)$ & $20(44)$ & 0.854 \\
\hline
\end{tabular}

Values given as mean \pm SD or number (\%)

$B M I$ body mass index, SAPS simplified acute physiology score, SOFA sepsis-related organ failure assessment, ARDS acute respiratory distress syndrome

$\mathrm{cmH}_{2} \mathrm{O}, p<0.001$, Fig. 2). Plateau pressure was also lower in survivors at day $90\left(22 \pm 6 \mathrm{cmH}_{2} \mathrm{O}\right)$ than in non-survivors $\left(24 \pm 6 \mathrm{cmH}_{2} \mathrm{O}, p=0.002\right.$, Table 2$)$, whereas Crs was higher in survivors $\left(37 \pm 19 \mathrm{ml} / \mathrm{cmH}_{2} \mathrm{O}\right)$ than in non-survivors $\left(29 \pm 11 \mathrm{ml} / \mathrm{cmH}_{2} \mathrm{O}, p<0.001\right.$, Table 2$)$.

In obese patients, the mortality rates in the ICU and at day 90 were $41 \%$ (95\% CI 31-51) and 46\% (95\% CI 36-56), respectively. At day 90, the driving pressure at day 1 did not differ between survivors $\left(14 \pm 5 \mathrm{cmH}_{2} \mathrm{O}\right)$ and nonsurvivors $\left(13 \pm 4 \mathrm{cmH}_{2} \mathrm{O}, p=0.408\right.$, Fig. 2). At day 90, the plateau pressure and $\mathrm{Crs}$ did not differ between survivors at day $90\left(25 \pm 5 \mathrm{cmH}_{2} \mathrm{O}\right.$ and $34 \pm 17 \mathrm{ml} / \mathrm{cmH}_{2} \mathrm{O}$, respectively) and non-survivors $\left(23 \pm 5 \mathrm{cmH}_{2} \mathrm{O}, p=0.258\right.$, and $35 \pm 16 \mathrm{ml} / \mathrm{cmH}_{2} \mathrm{O}, p=0.373$, respectively, Table 2).

Main and secondary outcomes including non-obese and obese patients according to the vital status at day 90 are summarized in Supplementary Table 3. The prognosis of obese and non-obese patients was not different. The prone position and neuromuscular blockers used for each class of obesity are detailed in Supplementary Table 4. In class II and III obesity, use of neuromuscular blockers and prone position was significantly more frequent than in non-obese patients $(p<0.05)$.

\section{Kaplan-Meier analysis}

Additional data about Kaplan-Meier analysis are available in the electronic supplementary content (results section, supplementary Fig. 1).

\section{Multivariate Cox analysis}

After multivariate analysis, there was a significant interaction among driving pressure, plateau pressure, $\mathrm{Crs}$ and obesity (Table 3 ). In non-obesepatients, driving pressure $[\mathrm{HR}=1.07$ (95\% CI 1.04-1.10, Table 3a) for each point of increase of driving pressure], plateau pressure $[\mathrm{HR}=1.04$ (95\% CI 1.01-1.07, Table 3b) for each point of increase of plateau pressure] and Crs $[\mathrm{HR}=0.97$ (95\% CI 0.960.99, Table 3c) for each point of increase of Crs] were 
Table 2 Ventilatory parameters in non-obese and obese patients, according to the vital status at day 90

\begin{tabular}{|c|c|c|c|c|c|c|c|c|}
\hline \multirow[t]{2}{*}{ Variables } & \multicolumn{2}{|c|}{ Overall $(n=362)$} & \multicolumn{2}{|c|}{ Non-obese $(n=262)$} & \multirow[t]{2}{*}{$p$} & \multicolumn{2}{|c|}{ Obese $(n=100)$} & \multirow[t]{2}{*}{$p$ value } \\
\hline & $\begin{array}{l}\text { Non-obese } \\
(n=262)\end{array}$ & Obese $(n=100)$ & $\begin{array}{l}\text { Survivors } \\
(n=140)\end{array}$ & $\begin{array}{l}\text { Non-survivors } \\
(n=122)\end{array}$ & & $\begin{array}{l}\text { Survivors } \\
(n=54)\end{array}$ & $\begin{array}{l}\text { Non-survivors } \\
(n=46)\end{array}$ & \\
\hline \multicolumn{9}{|l|}{ Biologic parameters } \\
\hline $\begin{array}{l}\text { Arterial pH on } \\
\text { day } 1\end{array}$ & $7.31 \pm 0.1$ & $7.35 \pm 0.1$ & $7.35 \pm 0.1$ & $7.28 \pm 0.18$ & $<0.001$ & $7.34 \pm 0.1$ & $7.29 \pm 0.18$ & 0.025 \\
\hline $\begin{array}{c}\mathrm{PaCO}_{2} \text { on day } 1, \\
\mathrm{mmHg}\end{array}$ & $43 \pm 6$ & $45 \pm 11$ & $44 \pm 11$ & $43 \pm 12$ & 0.495 & $46 \pm 12$ & $43 \pm 8$ & 0.413 \\
\hline $\begin{array}{l}\mathrm{PaO}_{2} \text { on day } 1, \\
\mathrm{mmHg}\end{array}$ & $87 \pm 36$ & $85 \pm 28$ & $88 \pm 37$ & $84 \pm 35$ & 0.186 & $79 \pm 16$ & $93 \pm 36$ & 0.214 \\
\hline $\begin{array}{l}\mathrm{PaO}_{2} / \mathrm{FIO}_{2} \text { ratio } \\
\text { on day } 1\end{array}$ & $123 \pm 57$ & $121 \pm 52$ & $124 \pm 54$ & $121 \pm 62$ & 0.314 & $114 \pm 47$ & $130 \pm 57$ & 0.137 \\
\hline $\begin{array}{l}\text { Bicarbonate on } \\
\text { day } 1, \mathrm{~g} / \mathrm{mol}\end{array}$ & $23 \pm 6$ & $23 \pm 5$ & $25 \pm 5$ & $21 \pm 6$ & $<0.001$ & $24 \pm 5$ & $21 \pm 6$ & 0.008 \\
\hline $\begin{array}{l}\text { Lactate on day } \\
1 \mathrm{mmol} / \mathrm{l}\end{array}$ & $4 \pm 5$ & $4 \pm 5$ & $2 \pm 2$ & $6 \pm 6$ & $<0.001$ & $2 \pm 2$ & $5 \pm 6$ & 0.003 \\
\hline \multicolumn{9}{|c|}{ Ventilation parameters } \\
\hline $\begin{array}{c}\text { Respiratory rate } \\
\text { on day } 1 / \text { min }\end{array}$ & $24 \pm 4$ & $24 \pm 4$ & $22 \pm 4$ & $25 \pm 6$ & 0.027 & $24 \pm 4$ & $24 \pm 5$ & 0.580 \\
\hline $\begin{array}{l}\text { Tidal volume on } \\
\text { day } 1, \mathrm{ml}\end{array}$ & $431 \pm 92$ & $450 \pm 79$ & $427 \pm 87$ & $435 \pm 99$ & 0.378 & $447 \pm 86$ & $452 \pm 71$ & 0.362 \\
\hline $\begin{array}{l}\text { Tidal volume } \\
\text { on day 1, ml/ } \\
\text { PBW kg }\end{array}$ & $7 \pm 1$ & $7 \pm 1$ & $7 \pm 1$ & $7 \pm 1$ & 0.442 & $7 \pm 1$ & $7 \pm 1$ & 0.821 \\
\hline $\begin{array}{l}\text { PEEP on day 1, } \\
\mathrm{CmH}_{2} \mathrm{O}\end{array}$ & $9 \pm 3$ & $10 \pm 3$ & $9 \pm 3$ & $8 \pm 3$ & 0.123 & $10 \pm 3$ & $9 \pm 3$ & 0.206 \\
\hline $\begin{array}{l}\text { Peak pressure } \\
\text { on day } 1 \text {, } \\
\mathrm{cmH}_{2} \mathrm{O}\end{array}$ & $35 \pm 8$ & $35 \pm 6$ & $35 \pm 8$ & $36 \pm 8$ & 0.914 & $37 \pm 5$ & $37 \pm 7$ & 0.173 \\
\hline $\begin{array}{l}\text { Plateau pres- } \\
\text { sure on day } 1 \text {, } \\
\mathrm{CmH}_{2} \mathrm{O}\end{array}$ & $23 \pm 6$ & $24 \pm 5$ & $22 \pm 6$ & $24 \pm 6$ & 0.002 & $25 \pm 5$ & $23 \pm 5$ & 0.258 \\
\hline $\begin{array}{c}\text { Plateau pres- } \\
\text { sure }<25 \\
\mathrm{cmH}_{2} \mathrm{O}\end{array}$ & $129(49)$ & $50(50)$ & $79(56)$ & $50(41)$ & 0.02 & $25(46)$ & $25(54)$ & 0.422 \\
\hline $\begin{array}{l}\text { Crs on day } 1 \\
\mathrm{ml} / \mathrm{cmH}_{2} \mathrm{O}\end{array}$ & $33 \pm 16$ & $34 \pm 16$ & $37 \pm 19$ & $29 \pm 11$ & $<0.001$ & $34 \pm 17$ & $35 \pm 16$ & 0.373 \\
\hline $\begin{array}{c}\mathrm{Crs}<31 \mathrm{ml} / \\
\quad \mathrm{CmH}_{2} \mathrm{O}\end{array}$ & $136(53)$ & $46(46)$ & $60(44)$ & $76(63)$ & 0.002 & $28(52)$ & $18(40)$ & 0.239 \\
\hline $\begin{array}{l}\text { Driving pres- } \\
\text { sure on day } 1 \text {, } \\
\mathrm{CmH}_{2} \mathrm{O}\end{array}$ & $13 \pm 5$ & $13 \pm 4$ & $12 \pm 4$ & $15 \pm 5$ & $<0.001$ & $14 \pm 5$ & $13 \pm 4$ & 0.408 \\
\hline $\begin{array}{l}\text { Driving pres- } \\
\text { sure }<14 \\
\mathrm{CmH}_{2} \mathrm{O}\end{array}$ & $134(51)$ & $54(54)$ & $86(69)$ & $48(39)$ & $<0.001$ & $29(54)$ & $25(54)$ & 0.949 \\
\hline $\begin{array}{l}\text { Mechanical } \\
\text { power on day } \\
1, \mathrm{~J} / \mathrm{min}\end{array}$ & $22 \pm 7$ & $24 \pm 6$ & $21 \pm 7$ & $22 \pm 7$ & 0.309 & $24 \pm 6$ & $24 \pm 6$ & 0.977 \\
\hline
\end{tabular}

Quantitative values are expressed as mean $\pm S D$, and qualitative values are numbers (percentage of group). Compliance of the respiratory system (Crs) was calculated as the ratio of tidal volume to driving pressure. Driving pressure was calculated as the difference between plateau pressure and applied positive end-expiratory pressure (PEEP). Mechanical power was calculated as the product of driving pressure in Newton $\left(\mathrm{cmH}_{2} \mathrm{O} \times 0.098\right)$, tidal volume and respiratory rate [36]. Day 1 was defined as the $24 \mathrm{~h}$ following the inclusion. The $\mathrm{PaO}_{2} / \mathrm{FIO}_{2}$ ratio is the ratio of the partial pressure of arterial oxygen to the fraction of inspired oxygen; $\mathrm{PaCO}$ is the partial pressure of arterial carbon dioxide; PBW is the predicted body weight

independently associated with day 90 mortality. In obese patients, driving pressure (Table 3a), plateau pressure (Table $3 \mathrm{~b}$ ) and Crs (Table 3c) were not independently associated with 90 -day mortality.
Additional data on the multivariate Cox analysis performed separately in non-obese and obese patients are available in the electronic supplemental content (results section, supplementary Table 5). 


Driving
pressure,
cm H2O

\section{Discussion}

This is the first study to assess the relationship between driving pressure and mortality in the specific population of obese critically ill ARDS patients. The major finding is that unlike non-obese ARDS patients, driving pressure was not associated with mortality in obese ARDS patients. These results were confirmed after survival and multivariate Cox analysis, showing that driving pressure was not a predictive factor of mortality in obese patients, contrary to non-obese patients. Similar results were found for plateau pressure and Crs.

Recently, Amato et al. [14] suggested that driving pressure was associated with mortality in ARDS. Moreover, Guérin et al. [15] confirmed these results in 2016 in a retrospective analysis of the PROSEVA and ACURAYSIS trials. However, in a recent retrospective observational analysis [17] performed in non-ARDS patients, driving pressure was not associated with hospital mortality.

The values of driving pressure found in the non-obese patients in the current study are in accordance with recently published studies. Guerin et al. [15] found that driving pressure averaged $13.7 \pm 3.7$ and $12.8 \pm 3.7 \mathrm{cmH}_{2} \mathrm{O}$ $(p=0.002)$ in non-survivors and survivors, respectively. Most recently, Bellani et al. [16] found that patients with a driving pressure $>14 \mathrm{cmH}_{2} \mathrm{O}$ at day 1 of the ARDS criteria had a higher mortality. This threshold of $14 \mathrm{cmH}_{2} \mathrm{O}$ was the one found in non-obese patients in the present study, reinforcing the external validity of these results.

The main explanations of the differences observed between the non-obese and obese groups may be the following. First, in obese patients, much of the pressure that is applied by the ventilator will be used to distend the chest wall rather than the lung. As such, the plateau pressure, which represents the pressure used to distend the chest wall plus lungs, may be high, but the pleural pressure will be too. Hence, there may not be an increase in transpulmonary pressure [27] with accompanying lung overdistension. Second, in relation to these physiologic changes, obese ARDS patients were found to be very different from non-obese ARDS patients in epidemiologic studies. Gong et al. [6] reported an association between increasing BMI and increasing development of ARDS. Higher BMI and obesity were associated with longer lengths of stay but not ARDS mortality after adjusting for baseline clinical factors [6]. Similarly to these results, Anzueto et al. [7] found that the obese patients were more likely to have significant complications during the course of ventilatory support including ARDS and acute renal failure, but there were no associations with increased duration of mechanical ventilation, length of stay or mortality. A recent study [28] confirmed these previous studies, showing that ICU mortality did not differ between obese and non-obese patients and that the medical category of admission was associated with worse prognosis than the surgical category of admission in obese ICU patients. One could hypothesize that ARDS in obese patients is a different entity that ARDS in nonobese patients. ARDS in obese patients may be less severe because of more atelectasis and less of the inflammatory process. The prone position was found to be associated with better outcomes in obese patients than in non-obese patients [8]. Better diaphragmatic function [29] in obese than in non-obese patients could also partly explain the specificities of ARDS in obese patients. 
Table 3 Results of multivariate Cox regression for the 90-day mortality prediction model

\begin{tabular}{|c|c|c|c|}
\hline Variable & B Parameter & $\mathrm{HR}(95 \% \mathrm{Cl})$ & $p$ value \\
\hline \multicolumn{4}{|c|}{ Model 1 including driving pressure } \\
\hline Driving pressure & 0.069 & & $<0.0001$ \\
\hline Obesity & 1.048 & & 0.0497 \\
\hline Driving pressure obesity & -0.079 & & 0.0354 \\
\hline $\begin{array}{l}\text { Driving pressure in non- } \\
\text { obese patients }\end{array}$ & & $1.07(1.04-1.10)$ & \\
\hline $\begin{array}{l}\text { Driving pressure in obese } \\
\text { patients }\end{array}$ & & $0.99(0.93-1.06)$ & \\
\hline SAPS $\|$ & 0.025 & $1.03(1.02-1.04)$ & 0.0003 \\
\hline SOFA at admission & 0.063 & $1.07(1.02-1.11)$ & 0.0039 \\
\hline $\begin{array}{l}\text { History of coronary artery } \\
\text { disease }\end{array}$ & 0.672 & $1.96(1.24-3.10)$ & 0.0041 \\
\hline \multicolumn{4}{|c|}{ Model 2 including plateau pressure } \\
\hline Plateau pressure & 0.041 & & 0.0078 \\
\hline Obesity & 1.429 & & 0.0966 \\
\hline Plateau pressure obesity & -0.062 & & 0.0840 \\
\hline $\begin{array}{l}\text { Plateau pressure in non- } \\
\text { obese patients }\end{array}$ & & $1.04(1.01-1.07)$ & \\
\hline $\begin{array}{l}\text { Plateau pressure in obese } \\
\text { patients }\end{array}$ & & $0.98(0.92-1.04)$ & \\
\hline SAPS $\|$ & 0.026 & $1.03(1.02-1.04)$ & $<0.0001$ \\
\hline SOFA at admission & 0.063 & $1.07(1.02-1.11)$ & 0.0038 \\
\hline $\begin{array}{l}\text { History of coronary artery } \\
\text { disease }\end{array}$ & 0.665 & $1.94(1.23-3.09)$ & 0.0047 \\
\hline \multicolumn{4}{|l|}{ Model 3 including Crs } \\
\hline Crs & -0.027 & & 0.0005 \\
\hline Obesity & -0.967 & & 0.0128 \\
\hline Crs obesity & -0.079 & & 0.0354 \\
\hline Crs in non-obese patients & & $0.97(0.96-0.99)$ & \\
\hline Crs in obese patients & & $1.00(0.99-1.02)$ & \\
\hline SAPS $\|$ & 0.027 & $1.03(1.02-1.04)$ & $<0.0001$ \\
\hline SOFA at admission & 0.065 & $1.07(1.02-1.11)$ & 0.0027 \\
\hline $\begin{array}{l}\text { History of coronary artery } \\
\text { disease }\end{array}$ & 0.689 & $1.99(1.26-3.15)$ & 0.0032 \\
\hline
\end{tabular}

HR for tidal compliance is presented for a one-point increase

$\mathrm{Cl}$ confidence interval, HR hazard ratio, SAPS simple acute physiologic score, SOFA sequential organ failure assessment, $\mathrm{Crs}$ compliance of the respiratory system

The current study has some limitations. First, the design was monocentric with a retrospective analysis, which limits the generalizability of the results. However, the data were collected prospectively with the ICU software, and the management of ARDS patients was standardized (lung-protective mechanical ventilation). Only $28 \%$ of the present study population was included in randomized controlled trials, and $72 \%$ of the study population was consequently a "real-life" observational population. This point allows an external validation of previous results obtained in non-obese patients issued only from randomized controlled trials $[14,15]$. Second, a few data are missing regarding the driving pressure $[5 / 105(5 \%)$ in obese patients and 28/290 (10\%) in non-obese patients]. Missing data were considered as MCAR after a sensitivity analysis using a best-worst case analysis, which allowed complete case analysis [30]. Third, although weight was determined on ICU admission, we cannot exclude the possibility that fluids given prior to admission may have affected the BMI. Fourth, the pattern of body fat distribution seems to be relevant to the changes in lung function observed in obese patients [31]. Changes in chest wall compliance are more affected by the amount of fat in both the chest and upper abdomen than by the amount of fat only in the chest, suggesting that respiratory system mechanics may differ in obese individuals with the same BMI but with different patterns of body fat distribution, which was not assessed in the current study. Future studies should be performed, separating abdominal from non-abdominal obesity.

The results of the current study suggest that driving pressure may not be appropriate to assess the severity of obese ARDS patients. A recent study examined the relationship between respiratory system and transpulmonary driving pressure, pulmonary mechanics and day-28 mortality [32]. The results suggest that utilizing PEEP titration to target positive transpulmonary pressure via esophageal manometry causes both improved elastance and driving pressures. Treatment strategies leading to decreased respiratory system and transpulmonary driving pressure at $24 \mathrm{~h}$ were found to be associated with improved 28-day mortality. In obese patients, Eichler et al. [33] showed that during laparoscopic bariatric surgery patients require high peroperative levels of PEEP to maintain positive transpulmonary pressure throughout the respiratory cycle. In the critical care setting, Pirrone et al. [34] first revealed that the commonly used positive end-expiratory pressure by clinicians is inadequate for optimal mechanical ventilation of morbidly obese patients, and then Fumagalli et al. [35] found that in obesity low-to-negative values of transpulmonary pressure predict lung collapse and intratidal recruitment/ derecruitment. Our results further support the use of transpulmonary pressure rather than driving pressure to monitor obese patients with ARDS, which could lead to higher set levels of PEEP in this specific population [33, 34], to work against derecruitment.

\section{Conclusions}

Contrary to non-obese ARDS patients, 90-day mortality was not associated with higher driving pressure across the respiratory system in obese ARDS patients. We suspected that pre-defined ventilator settings that are similar for obese and non-obese patients may not be appropriate for both since PEEP requirements and the resulting driving pressure of the respiratory system might vary widely among patients because of their individual anatomy and 
physiology. Measuring transpulmonary pressure using esophageal pressure could be of interest in obese patients as a prognostic factor of mortality and to optimize the ventilatory settings (i.e., individualized PEEP).

\section{Electronic supplementary material}

The online version of this article (https://doi.org/10.1007/s00134-018-5241-6) contains supplementary material, which is available to authorized users.

\begin{abstract}
Author details
${ }^{1}$ Anesthesiology and Intensive Care; Anesthesia and Critical Care Department B, Saint Eloi Teaching Hospital, PhyMedExp, University of Montpellier, INSERM U1046, CNRS, UMR 9214, 80 Avenue Augustin Fliche, 34295 Montpellier Cedex 5, France. ${ }^{2}$ Anesthesiology and Intensive Care; Anesthesia and Critical Care Department B, Saint Eloi Teaching Hospital, Montpellier Cedex 5 34295, France. ${ }^{3}$ Department of Statistics, University of Montpellier Lapeyronie Hospital, UMR 729, MISTEA, Montpellier, France.
\end{abstract}

\section{Author contributions}

AJ contributed to the conception and design of the study, analysis and interpretation of data, drafting the submitted article and providing the final approval of the version to be published. JC contributed to acquisition of the data, analysis of the data, drafting the submitted article and providing final approval of the version to be published. DV contributed to the acquisition of the data and providing the final approval of the version to be published. CM contributed to the acquisition of the data and to providing final approval of the version to be published. JC contributed to the acquisition of data and drafting the submitted article. MC contributed to the acquisition of the data and providing final approval of the version to be published. MC contributed to the acquisition of the data and providing final approval of the version to be published. FB contributed to the acquisition of the data and providing final approval of the version to be published. NM contributed to the acquisition of the data and providing final approval of the version to be published. GC contributed to the analysis and interpretation of the data and to providing final approval of the version to be published. SJ contributed to the conception and design of the study, analysis and interpretation of data, drafting the submitted article and providing final approval of the version to be published.

\section{Funding}

Support was provided solely from institutional and/or departmental sources.

\section{Compliance with ethical standards}

\section{Conflicts of interest}

Dr. Jaber reports receiving consulting fees from Drager, Hamilton, Maquet and Fisher \& Paykel. No potential conflict of interest relevant to this article was reported for other authors.

\section{Ethical approval}

Approval from the local scientific and ethics committee of the "Comite d'Organisation et de Gestion de l'Anesthésie Réanimation" (COGAR) of the Montpellier University Hospital was obtained; they stated that no informed consent of the patient or next of kin was required because there was no change in care practices.

Received: 8 March 2018 Accepted: 22 May 2018 Published online: 15 June 2018

\section{References}

1. Afshin A, Forouzanfar MH, Reitsma MB, Sur P, Estep K, Lee A, Marczak L, Mokdad AH, Moradi-Lakeh M, Naghavi M, Salama JS, Vos T, Abate KH, Abbafati C, Ahmed MB, Al-Aly Z, Alkerwi A, Al-Raddadi R, Amare AT, Amberbir A, Amegah AK, Amini E, Amrock SM, Anjana RM, Arnlov J, Asayesh H, Banerjee A, Barac A, Baye E, Bennett DA, Beyene AS, Biadgilign S, Biryukov S, Bjertness E, Boneya DJ, Campos-Nonato I, Carrero JJ, Cecilio
P, Cercy K, Ciobanu LG, Cornaby L, Damtew SA, Dandona L, Dandona R, Dharmaratne SD, Duncan BB, Eshrati B, Esteghamati A, Feigin VL, Fernandes JC, Furst T, Gebrehiwot TT, Gold A, Gona PN, Goto A, Habtewold TD, Hadush KT, Hafezi-Nejad N, Hay SI, Horino M, Islami F, Kamal R, Kasaeian A, Katikireddi SV, Kengne AP, Kesavachandran CN, Khader YS, Khang YH, Khubchandani J, Kim D, Kim YJ, Kinfu Y, Kosen S, Ku T, Defo BK, Kumar GA, Larson HJ, Leinsalu M, Liang X, Lim SS, Liu P, Lopez AD, Lozano R, Majeed A, Malekzadeh R, Malta DC, Mazidi M, McAlinden C, McGarvey ST, Mengistu DT, Mensah GA, Mensink GBM, Mezgebe HB, Mirrakhimov EM, Mueller UO, Noubiap JJ, Obermeyer CM, Ogbo FA, Owolabi MO, Patton GC, Pourmalek F, Qorbani M, Rafay A, Rai RK, Ranabhat CL, Reinig N, Safiri S, Salomon JA, Sanabria JR, Santos IS, Sartorius B, Sawhney M, Schmidhuber J, Schutte AE, Schmidt MI, Sepanlou SG, Shamsizadeh M, Sheikhbahaei S, Shin MJ, Shiri R, Shiue I, Roba HS, Silva DAS, Silverberg Jl, Singh JA, Stranges S, Swaminathan S, Tabares-Seisdedos R, Tadese F, Tedla BA, Tegegne BS, Terkawi AS, Thakur JS, Tonelli M, Topor-Madry R, Tyrovolas S, Ukwaja KN, Uthman OA, Vaezghasemi M, Vasankari T, Vlassov VV, Vollset SE, Weiderpass E, Werdecker A, Wesana J, Westerman R, Yano Y, Yonemoto N, Yonga G, Zaidi Z, Zenebe ZM, Zipkin B, Murray CJL (2017) Health effects of overweight and obesity in 195 countries over 25 years. N Engl J Med 377:13-27

2. Montravers $P$, Ribeiro-Parenti $L$, Welsch C (2015) What's new in postoperative intensive care after bariatric surgery? Intensive Care Med 41:1114-1117

3. De Jong A, Molinari N, Pouzeratte Y, Verzilli D, Chanques G, Jung B, Futier E, Perrigault PF, Colson P, Capdevila X, Jaber S (2015) Difficult intubation in obese patients: incidence, risk factors, and complications in the operating theatre and in intensive care units. Br J Anaesth 114:297-306

4. Pepin JL, Timsit JF, Tamisier R, Borel JC, Levy P, Jaber S (2016) Prevention and care of respiratory failure in obese patients. Lancet Respir Med 4:407-418

5. Mahul M, Jung B, Galia F, Molinari N, de Jong A, Coisel Y, Vaschetto R, Matecki S, Chanques G, Brochard L, Jaber S (2016) Spontaneous breathing trial and post-extubation work of breathing in morbidly obese critically ill patients. Crit Care 20:346

6. Gong MN, Bajwa EK, Thompson BT, Christiani DC (2010) Body mass index is associated with the development of acute respiratory distress syndrome. Thorax 65:44-50

7. Anzueto A, Frutos-Vivar F, Esteban A, Bensalami N, Marks D, Raymondos K, Apezteguía C, Arabi Y, Hurtado J, González M, Tomicic V, Abroug F, Elizalde J, Cakar N, Pelosi P, Ferguson ND, Ventila Group (2011) Influence of body mass index on outcome of the mechanically ventilated patients. Thorax 66:66-73

8. De Jong A, Molinari N, Sebbane M, Prades A, Futier E, Jung B, Chanques G, Jaber S (2013) Feasibility and effectiveness of prone position in morbidly obese patients with ARDS: a case-control clinical study. Chest 143:1554-1561

9. Delay J-M, Sebbane M, Jung B, Nocca D, Verzilli D, Pouzeratte Y, Kamel ME, Fabre J-M, Eledjam J-J, Jaber S (2008) The effectiveness of noninvasive positive pressure ventilation to enhance preoxygenation in morbidly obese patients: a randomized controlled study. Anesth Analg 107:1707-1713

10. Futier E, Constantin JM, Pelosi P, Chanques G, Massone A, Petit A, Kwiatkowski F, Bazin JE, Jaber S (2011) Noninvasive ventilation and alveolar recruitment maneuver improve respiratory function during and after intubation of morbidly obese patients: a randomized controlled study. Anesthesiology 114:1354-1363

11. De Jong A, Futier E, Millot A, Coisel Y, Jung B, Chanques G, Baillard C, Jaber $S$ (2014) How to preoxygenate in operative room: healthy subjects and situations "at risk". Ann Fr Anesth Reanim 33:457-461

12. Constantin JM, Jaber S (2012) Preoxygenation in obese patient with noninvasive pressure support ventilation: keep the pressure. Ann Fr Anesth Reanim 31:673-674

13. O'Brien JM Jr, Philips GS, Ali NA, Aberegg SK, Marsh CB, Lemeshow S (2012) The association between body mass index, processes of care, and outcomes from mechanical ventilation: a prospective cohort study. Crit Care Med 40:1456-1463

14. Amato MB, Meade MO, Slutsky AS, Brochard L, Costa EL, Schoenfeld DA Stewart TE, Briel M, Talmor D, Mercat A, Richard JC, Carvalho CR, Brower RG (2015) Driving pressure and survival in the acute respiratory distress syndrome. N Engl J Med 372:747-755 
15. Guerin C, Papazian L, Reignier J, Ayzac L, Loundou A, Forel JM (2016) Effect of driving pressure on mortality in ARDS patients during lung protective mechanical ventilation in two randomized controlled trials. Crit Care 20:384

16. Bellani G, Laffey JG, Pham T, Fan E, Brochard L, Esteban A, Gattinoni L, van Haren F, Larsson A, McAuley DF, Ranieri M, Rubenfeld G, Thompson BT, Wrigge H, Slutsky AS, Pesenti A (2016) Epidemiology, patterns of care, and mortality for patients with acute respiratory distress syndrome in intensive care units in 50 countries. JAMA 315:788-800

17. Schmidt MFS, Amaral A, Fan E, Rubenfeld GD (2017) Driving pressure and hospital mortality in patients without ards: a cohort study. Chest 153:46-56

18. Villar J, Martin-Rodriguez C, Dominguez-Berrot AM, Fernandez L, Ferrando C, Soler JA, Diaz-Lamas AM, Gonzalez-Higueras E, Nogales L, Ambros A, Carriedo D, Hernandez M, Martinez D, Blanco J, Belda J, Parrilla D, SuarezSipmann F, Tarancon C, Mora-Ordonez JM, Blanch L, Perez-Mendez L, Fernandez RL, Kacmarek RM (2017) A quantile analysis of plateau and driving pressures: effects on mortality in patients with acute respiratory distress syndrome receiving lung-protective ventilation. Crit Care Med 45:843-850

19. Aoyama H, Pettenuzzo T, Aoyama K, Pinto R, Englesakis M, Fan E (2017) Association of driving pressure with mortality among ventilated patients with acute respiratory distress syndrome: a systematic review and metaanalysis. Crit Care Med 46:300-306

20. De Jong A, Chanques G, Jaber S (2017) Mechanical ventilation in obese ICU patients: from intubation to extubation. Crit Care 21:63

21. (1998) Executive summary of the clinical guidelines on the identification, evaluation, and treatment of overweight and obesity in adults. Arch Intern Med 158:1855-1867

22. Ranieri VM, Rubenfeld GD, Thompson BT, Ferguson ND, Caldwell E, Fan E, Camporota L, Slutsky AS (2012) Acute respiratory distress syndrome: the Berlin Definition. JAMA 307:2526-2533

23. De Jong A, Deras P, Martinez O, Latry P, Jaber S, Capdevila X, Charbit J (2016) Relationship between obesity and massive transfusion needs in trauma patients, and validation of tash score in obese population: a retrospective study on 910 trauma patients. PLoS One 11:e0152109

24. Guérin C, Reignier J, Richard J-C, Beuret P, Gacouin A, Boulain T, Mercier E, Badet M, Mercat A, Baudin O, Clavel M, Chatellier D, Jaber S, Rosselli S, Mancebo J, Sirodot M, Hilbert G, Bengler C, Richecoeur J, Gainnier M, Bayle F, Bourdin G, Leray V, Girard R, Baboi L, Ayzac L, Group PS (2013) Prone positioning in severe acute respiratory distress syndrome. N Engl J Med 368:2159-2168

25. Early Spontaneous Breathing in Acute Respiratory Distress Syndrome (BiRDS). https://clinicaltrials.gov/ct2/show/NCT01862016. Accessed 20 Feb 2018

26. Jabaudon M, Godet T, Futier E, Bazin JE, Sapin V, Roszyk L, Pereira B, Constantin JM (2017) Rationale, study design and analysis plan of the lung imaging morphology for ventilator settings in acute respiratory distress syndrome study (LIVE study): study protocol for a randomised controlled trial. Anaesth Crit Care Pain Med 36:301-306

27. Mauri T, Yoshida T, Bellani G, Goligher EC, Carteaux G, Rittayamai N, Mojoli F, Chiumello D, Piquilloud L, Grasso S, Jubran A, Laghi F, Magder S, Pesenti A, Loring S, Gattinoni L, Talmor D, Blanch L, Amato M, Chen L, Brochard L, Mancebo J (2016) Esophageal and transpulmonary pressure in the clinical setting: meaning, usefulness and perspectives. Intensive Care Med 42:1360-1373

28. De Jong A, Verzilli D, Sebbane M, Monnin M, Belafia F, Cisse M, Conseil M, Carr J, Jung B, Chanques G, Molinari N, Jaber S (2018) Medical versus surgical ICU obese patient outcome: a propensity-matched analysis to resolve clinical trial controversies. Crit Care Med 46:e294

29. De Jong A, Carreira S, Na N, Carillion A, Jiang C, Beuvin M, Lacorte JM, Bonnefont-Rousselot D, Riou B, Coirault C (2017) Diaphragmatic function is enhanced in fatty and diabetic fatty rats. PLoS One 12:e0174043

30. Mukaka M, White SA, Terlouw DJ, Mwapasa V, Kalilani-Phiri L, Faragher EB (2016) Is using multiple imputation better than complete case analysis for estimating a prevalence (risk) difference in randomized controlled trials when binary outcome observations are missing? Trials 17:341

31. Mafort TT, Rufino R, Costa CH, Lopes AJ (2016) Obesity: systemic and pulmonary complications, biochemical abnormalities, and impairment of lung function. Multidiscip Respir Med 11:28

32. Baedorf Kassis E, Loring SH, Talmor D (2016) Mortality and pulmonary mechanics in relation to respiratory system and transpulmonary driving pressures in ARDS. Intensive Care Med 42:1206-1213

33. Eichler L, Truskowska K, Dupree A, Busch P, Goetz AE, Zollner C (2017) Intraoperative ventilation of morbidly obese patients guided by transpulmonary pressure. Obes Surg 8:122-129

34. Pirrone M, Fisher D, Chipman D, Imber DA, Corona J, Mietto C, Kacmarek RM, Berra L (2016) Recruitment maneuvers and positive end-expiratory pressure titration in morbidly obese ICU patients. Crit Care Med 44:300-307

35. Fumagalli J, Berra L, Zhang C, Pirrone M, Santiago RRS, Gomes S, Magni F, Dos Santos GAB, Bennett D, Torsani V, Fisher D, Morais C, Amato MBP, Kacmarek RM (2017) Transpulmonary pressure describes lung morphology during decremental positive end-expiratory pressure trials in obesity. Crit Care Med 45:1374-1381

36. Gattinoni $L$, Tonetti $T$, Cressoni M, Cadringher $P$, Herrmann $P$, Moerer $O$, Protti A, Gotti M, Chiurazzi C, Carlesso E, Chiumello D, Quintel M (2016) Ventilator-related causes of lung injury: the mechanical power. Intensive Care Med 42:1567-1575 